\title{
Long Pulse Fusion Physics Experiments Without Superconducting Electromagnets
}

\author{
Robert D. Woolley \\ Princeton University \\ Princeton Plasma Physics Laboratory* \\ P.O. Box 451, Princeton, New Jersey 08543
}

(609) 243-3130

*Supported by U.S.Department of Energy Contract No. DE-AC02-76CH03073.

\section{ABSTRACT}

Long pulse fusion physics experiments can be performed economically via resistive electromagnets designed for thermally steady-state operation. Possible fusion experiments using resistive electromagnets include long pulse ignition with DT fuel. ., $^{1,3,4}$ Long pulse resistive electromagnets are alternatives to today's delicate and costly superconductors. ${ }^{5}$ At any rate, superconducting technology is now evolving independent of fusion, so near-term superconducting experience may not ultimately be useful.

High magnetic field copper coils can be operated for long pulses if actively cooled by subcooled liquid nitrogen, thermally designed for steady state operation. (Optimum cooling parameters are characterized herein.) This cooling scheme uses the thermal mass of an external liquid nitrogen reservoir to absorb the long pulse resistive magnet heating. Pulse length is thus independent of device size and is easily extended. This scheme is most effective if the conductor material is OFHC copper, whose resistivity at liquid nitrogen temperature is small. Active $\mathrm{LN}_{2}$ cooling also allows slow TF ramp-up and avoids high resistance during current flattop; these factors reduce power system cost relative to short pulse adiabatic designs.

\section{INTRODUCTION}

The main design issue for long pulse resistive electromagnets is heat removal (within stress limitations). Successful designs can employ thermally steady cooling via forced convection of a liquid coolant, pressurized to prevent film boiling. True steady-state operation would require the warmed coolant fluid to be continuously recooled, but for intermittent long pulse operation the warmed fluid can be stored in a reservoir and recooled later between pulses.

Although choosing water as the coolant has some practical advantages (e.g., economy, high heat capacity, and the ability to exhaust steady magnet heat directly into the environment without any refrigeration system), the consequent "room temperature" magnet operation can require a costly electric power system capability. But since resistive power is proportional to conductor resistivity (see Figure 1) the alternative use of a cryogen as combined coolant and thermal mass for intermittent long pulse operation can greatly reduce resistive electric power consumption, which eases the heat removal task while also reducing capital cost requirements for the electrical power system. Liquid nitrogen is a natural choice for the cryogen. A byproduct of industrial oxygen production, it is cheaply available by the truckload in many locations, and so does not necessarily require the purchase of a cryogenic refrigerator. Large insulated dewar tanks to store it are available and inexpensive. It is nontoxic and can be released safely into the environment. It is not chemically explosive as are some cryogens. It is almost inert chemically and will not attack any materials used in magnet construction. It is also an excellent electrical insulator. ${ }^{6}$

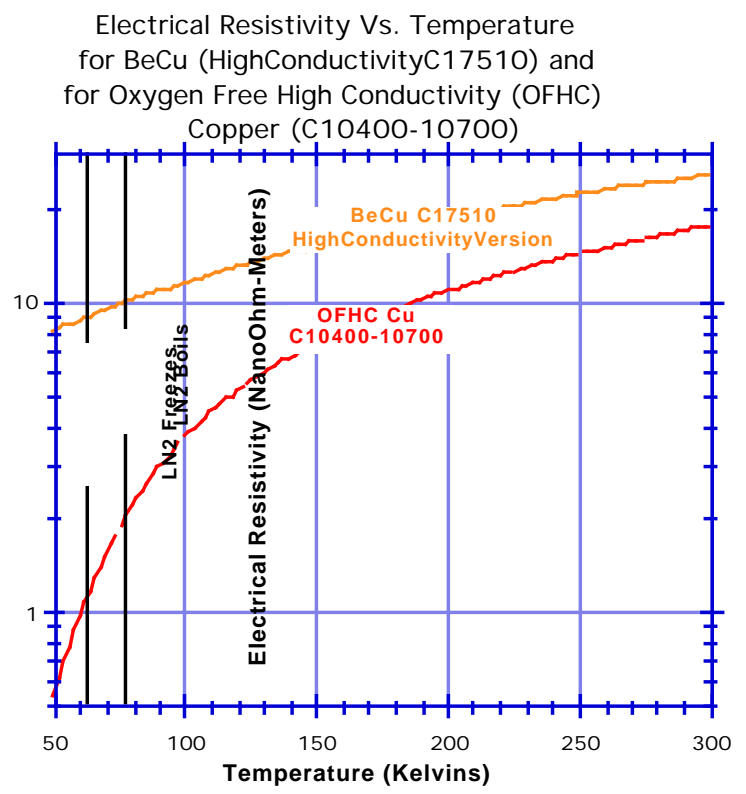

Figure 1:Copper Alloy and Copper Resistivity

A particularly simple design concept is a "once-through" system employing two identical large storage dewars with interconnected gas spaces, as depicted in Figure 2. One dewar is initially filled with liquid nitrogen at atmospheric pressure but subcooled to nitrogen's $63.2^{\circ} \mathrm{K}$ triple point temperature, while the second dewar is initially empty. During the long pulse, liquid nitrogen from the first dewar is pumped through cooling passages in the electromagnets sufficiently fast that its exit temperature does not exceed liquid nitrogen's $77.4^{\circ} \mathrm{K}$ normal boiling point. Exiting liquid nitrogen flows into the second dewar at atmospheric pressure. During time intervals between pulses the nitrogen is returned to the first dewar and recooled to the triple point. Useful features of this long pulse scheme include:

-No real-time coolant release to the atmosphere is involved.

(This safety feature is important if coolant nitrogen becomes temporarily activated by DT neutrons.) 
-Long pulse duration can be extended arbitrarily without reengineering the fusion experiment's magnet system, by simply installing more liquid nitrogen storage dewars.

- Coolant and thermal mass storage is, economically, at atmospheric pressure.

-No real-time heat transfer during the long pulse is required except inside the electromagnets.

-Steady electromagnet electric power is greatly reduced below that of water-cooled room-temperature designs.

-No on-site electrical energy storage system is required to quickly ramp up the toroidal magnetic field, i.e., the TF electric power system rating can be based on steady losses.

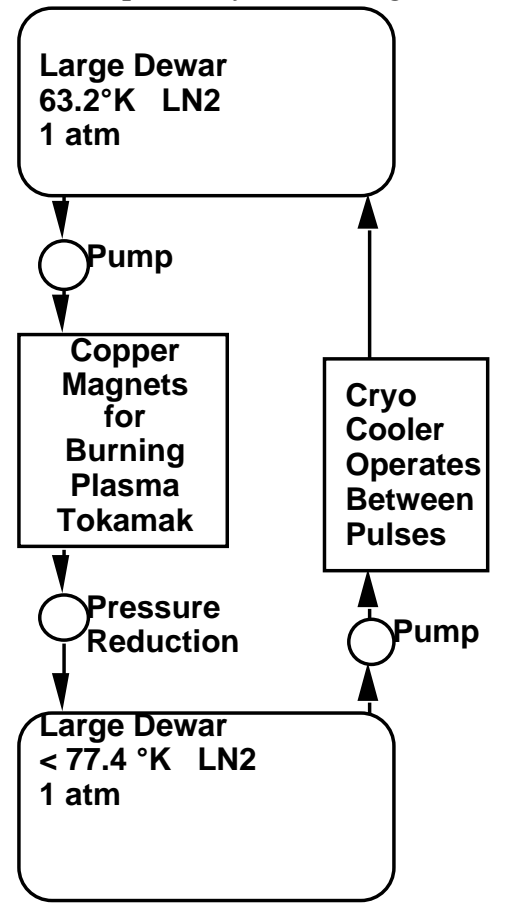

Figure 2: “Once-Through” Long Pulse Concept

Recooling of the $77.4^{\circ} \mathrm{K}$ liquid nitrogen can be unconventionally but cheaply implemented via a simple pumping system containing a section in which liquid pressure is reduced to nitrogen's $1 / 8$ atmosphere triple point pressure. This evaporative recooling approach does not necessitate purchasing a cryogenic refrigerator nor even a heat exchanger. Energy released from the temperature reduction via liquid nitrogen's specific heat $\left(c_{p}\right)$ is balanced by energy absorbed by its heat of vaporization $\left(\mathrm{h}_{\mathrm{fg}}\right)$, as about $15 \%$ of the $77.4^{\circ} \mathrm{K}$ liquid nitrogen flashes to the gaseous state. Repressurization of the separated $63.2^{\circ} \mathrm{K}$ liquid stream does not significantly raise its temperature above the triple point, so the liquid emerges at atmospheric pressure near its freezing point temperature. Repressurization of the separated gas stream to atmospheric pressure raises its temperature to about $105^{\circ} \mathrm{K}$. In the least capital cost implementation the nitrogen gas is exhausted into the atmosphere and replaced by purchased liquid nitrogen. In the least operating cost implementation a local cryogenic refrigerator reliquifies the $105^{\circ} \mathrm{K}$ nitrogen gas.

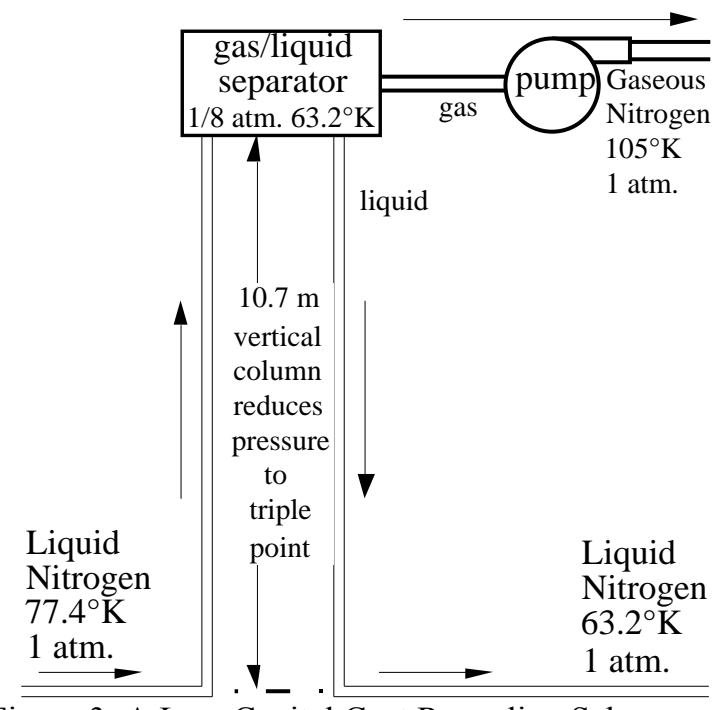

Figure 3: A Low Capital Cost Recooling Scheme

Figure 3 depicts a version of this recooling concept in which gravity helps provide the required pressure changes and the process is driven by a single pressure reduction pump.

\section{SIMPLE THERMAL-HYDRAULIC RELATIONS}

Since design of an actively cooled electromagnet requires choosing many parameters, it is useful to review the relationships between them and how to choose them for best performance. This has been examined in the past, e.g. by R. Kronauer. ${ }^{7}$ His approach is repeated here but is updated to use SI units and today's generally accepted models for pressure drop and heat transfer, specialized for subcooled liquid nitrogen active cooling as proposed herein. ${ }^{8,9}$ It should be noted, however, that this development is incomplete since it requires conductor resistivity to be estimated a priori. Actually, increased active cooling will reduce conductor temperature, resistivity, and dissipated power, thus reducing the need for active cooling.

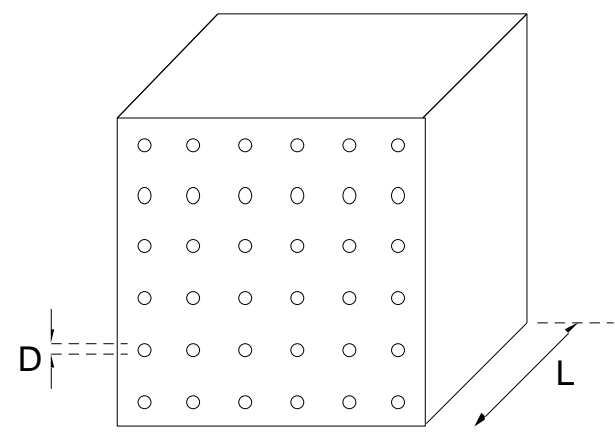

Figure 4: Schematic of Cooling Channels in Conductor

We initially consider a conductor volume, $\mathrm{V}$, carrying a specified average current density, J'. Let $\eta$ be the conductor's electrical resistivity. Then P', the resistive electric power density which would be dissipated if none of the conductor volume were removed, is

$$
\mathrm{P}^{\prime}=\eta \mathrm{J}^{, 2}
$$


and the total power dissipated in the volume is $\eta \mathrm{J}^{, 2} \mathrm{~V}$.Let a fraction of the volume, $\beta$, be removed to form some identical coolant channels. The volume of material removed is $\beta \mathrm{V}$ and the remaining volume of conductor is $(1-\beta) \mathrm{V}$. The average current density in the now smaller conductor is

$$
\mathrm{J}=\mathrm{J} '(1-\beta) \text {. }
$$

Dissipated power in the volume is $\eta(\mathrm{J} /(1-\beta))^{2}(1-\beta) \mathrm{V}$, so the new power density (based on the original volume, $V$ ) is

$$
P_{\text {diss }}=P^{\prime} /(1-\beta)
$$

For noncircular coolant channel cross-sections (see Figure 5) with area $\mathrm{A}$ and perimeter $\mathrm{C}$, the hydraulic diameter is

$$
\mathrm{D}=4 \mathrm{~A} / \mathrm{C}
$$

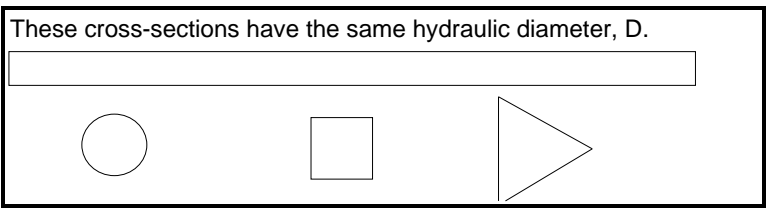

Figure 5: Noncircular Coolant Channel Cross-sections

$\mathrm{L}$ is a coolant channel's length in the flow direction, so its heat transfer surface area is CL. The volume of a single coolant channel is $\mathrm{AL}$, so the number of channels in the original volume is $\beta \mathrm{V} /(\mathrm{AL})$. Total heat transfer surface area in the original volume is $(\mathrm{CL})(\beta \mathrm{V} /(\mathrm{AL}))=4 \beta \mathrm{V} / \mathrm{D}$, so total heat transfer surface area per cubic meter is $4 \beta / \mathrm{D}$.

$\mathrm{U}$ is the average velocity of coolant fluid flowing in a coolant channel, and the Reynolds number is $\mathrm{Re}=\rho \mathrm{UD} / \mu$ where $\rho$ and $\mu$ are $L_{2}$ 's mass density and viscosity. Turbulent flow friction causes a pressure drop in the coolant channel given by the Darcy-Weisbach formula,

$$
\Delta \mathrm{p}=(\mathrm{L} / \mathrm{D}) \rho \mathrm{U}^{2} \mathrm{f}(\mathrm{Re}) / 2,
$$

where the friction factor, $f$, depends on the Reynolds number through Colebrook's equation for smooth-walled passages:

$$
\mathrm{f}=1 /\left(2 \log _{10}(\mathrm{Re})-0.8+\log _{10} \mathrm{f}\right)^{2} .
$$

Pumping power for the original volume, $\mathrm{V}$, is the product of pressure drop, $\Delta \mathrm{p}$, and volumetric flow rate, $\beta \mathrm{UV} / \mathrm{L}$. Considering the pump efficiency, $\zeta$, the power density per original cubic meter required for coolant pumping is

$$
\mathrm{P}_{\text {pump }}=\Delta \mathrm{p} \beta \mathrm{U} /(\mathrm{L} \zeta)
$$

Total power consumed per original cubic meter is then

$$
\begin{aligned}
\mathrm{P}_{\text {total }} & =\mathrm{P}_{\text {diss }}+\mathrm{P}_{\text {pump }} \\
& =\mathrm{P}^{\prime} /(1-\beta)+\beta \rho \mathrm{U}^{3} \mathrm{f}(\rho \mathrm{UD} / \mu) /(2 \mathrm{D} \zeta)
\end{aligned}
$$

Flow friction raises bulk coolant temperature as:

$$
\Delta \mathrm{T}_{\mu}=\Delta \mathrm{p} /\left(\rho \mathrm{C}_{\mathrm{p}}\right)
$$

where $\mathrm{C}_{\mathrm{p}}$ is $\mathrm{LN}_{2}$ 's specific heat at constant pressure. The rise in bulk coolant temperature because of absorbed electrical dissipation power is

$$
\Delta \mathrm{T}_{\mathrm{e}}=\left(\mathrm{L} /\left(\mathrm{U} \rho \mathrm{C}_{\mathrm{p}}\right)\right) \mathrm{P}^{\prime} /(\beta(1-\beta))
$$

The heat transfer film drop is the heat flux divided by the heat transfer coefficient, h, i.e.

$$
\begin{array}{r}
\Delta \mathrm{T}_{\overline{\mathrm{f}}}\left(\left(\mathrm{P}^{\prime} /(1-\beta)\right) /(4 \beta / \mathrm{D})\right) / \mathrm{h} \\
=\mathrm{DP}^{\prime} /(4 \mathrm{~h} \beta(1-\beta))
\end{array}
$$

where $\mathrm{h}$ is governed by the Dittus-Boelter correlation,

$$
\mathrm{Nu}=0.0243 \mathrm{Re}^{0.8} \operatorname{Pr}^{0.4}
$$

where $\mathrm{Nu}=\mathrm{hD} / \mathrm{k}$ is the flowing coolant's Nusselt number, where $\operatorname{Pr}=\mu \mathrm{C}_{\mathrm{p}} / \mathrm{k}$ is its Prandtl number, and where $\mathrm{k}$ is its thermal conductivity. Then the temperature difference between the the cold coolant supplied to the electromagnet and the conductor surface at the coolant channel exit is

$$
\Delta \mathrm{T}_{0}=\Delta \mathrm{T}_{\mathrm{e}}+\Delta \mathrm{T}_{\mu}+\Delta \mathrm{T}_{\mathrm{f}}
$$

Some liquid nitrogen property values useful in the evaluation of these formulas are given in Table 1..$^{10,11}$

Table 1: Relevant Liquid Nitrogen Properties

\begin{tabular}{|l|l|l|l|l|l|}
\hline Parameter & $63.2^{\circ} \mathrm{K}$ & $65^{\circ} \mathrm{K}$ & $70^{\circ} \mathrm{K}$ & $75^{\circ} \mathrm{K}$ & $77.36^{\circ} \mathrm{K}$ \\
\hline $\mathrm{p}_{\text {sat }}(\mathrm{kPa})$ & 12.8 & 17.4 & 38.5 & 76.0 & 101.3 \\
\hline$\rho_{\mathrm{f}}\left(\mathrm{kg} / \mathrm{m}^{3}\right)$ & 870 & 860.9 & 840.0 & 818.1 & 807.3 \\
\hline $\mathrm{h}_{\mathrm{fg}}(\mathrm{kJ} / \mathrm{kg})$ & 216 & 214.0 & 208.3 & 202.3 & 199.3 \\
\hline $\mathrm{c}_{\mathrm{p}}\left(\mathrm{J} / \mathrm{kg}^{\circ} \mathrm{K}\right)$ & 2000 & 2008 & 2024 & 2042 & 2051 \\
\hline$\mu(\mu \mathrm{Pa}-\mathrm{s})$ & 300 & 278 & 220 & 173 & 158 \\
\hline $\mathrm{k}\left(\mathrm{w} / \mathrm{m}^{\circ} \mathrm{K}\right)$ & 0.163 & 0.159 & 0.150 & 0.143 & 0.140 \\
\hline $\operatorname{Pr}$ & 3.7 & 3.52 & 2.97 & 2.47 & 2.32 \\
\hline
\end{tabular}

\section{OPTIMIZATION}

The simple formulas above map from the five variables, $\mathrm{P}^{\prime}, \mathrm{L}, \mathrm{D}, \mathrm{U}, \beta$, and coolant properties into $\Delta \mathrm{T}_{0}, \mathrm{P}_{\text {total }}$, and other parameters. For each specified ( $\left.\mathrm{P}^{\prime}, \mathrm{L}\right)$ pair, the optimization procedure jointly varies $D, U, \beta$, in order to minimize $P_{\text {total }}$ while satisfying an equality constraint on $\Delta \mathrm{T}_{0}$. For these calculations $\Delta \mathrm{T}_{0}$ was held equal to $15^{\circ} \mathrm{K}$ since that resulted in $\mathrm{LN}_{2}$ bulk temperature rises near $10^{\circ} \mathrm{K}$, a practical design target. $\mathrm{LN}_{2}$ coolant properties for $70^{\circ} \mathrm{K}$ were used. Figures 6-9 summarize the optimized results for a range of $\left(\mathrm{P}^{\prime}, \mathrm{L}\right)$ values. Solid lines in these plots restrict coolant velocity to not exceed $12 \mathrm{~m} / \mathrm{s}$, the highest velocity for which published heat transfer test data were found. (Technology exists for aggressive cryogenic pumping, e.g., developed for rocketry applications.) 


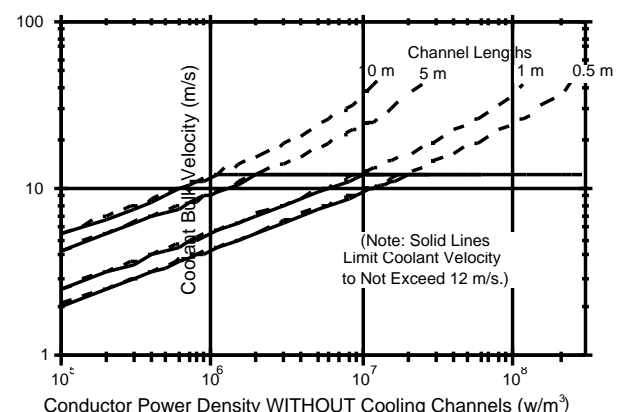

Figure 6: Optimized Subcooled LN Coolant Velocity Size/Power Scaling

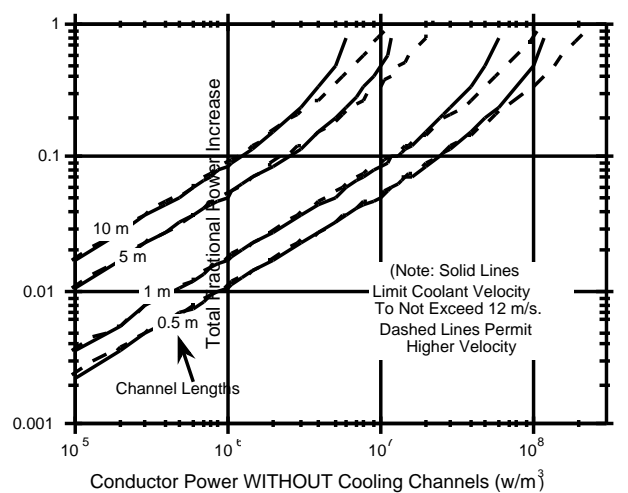

Figure 7: Additional Per Unit Power Required, Including Both Coolant Pumping Power Plus Power From Heightened Current Density, With Coolant Channel Conductor Removed

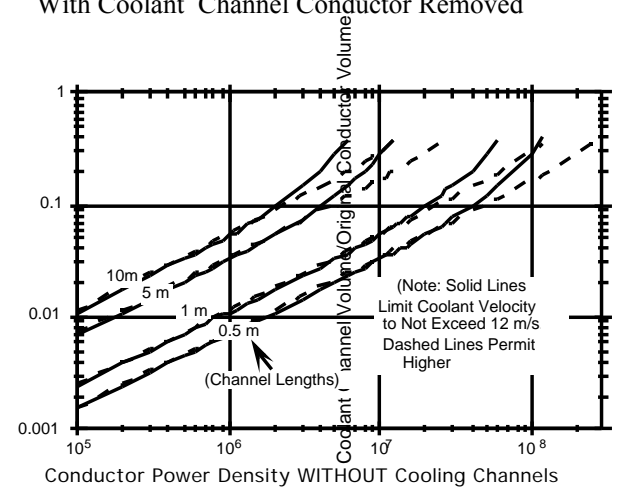

Figure 8: Size/Power Scaling of Optimal Conductor Fraction Removed for Subcooled LN2 Cooling Channels

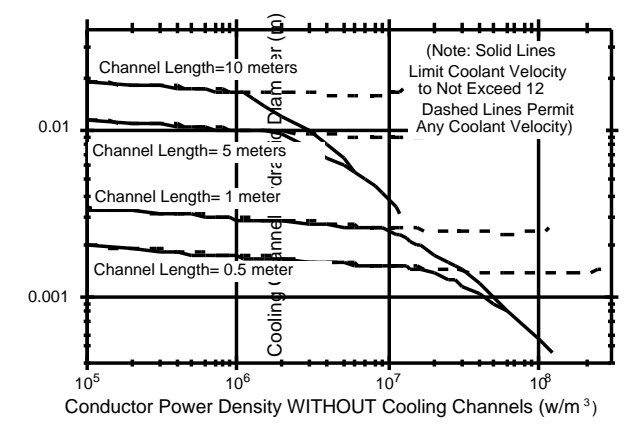

Figure 9: Optimum Subcooled $\mathrm{LN}_{2}$ Cooling Channel Size/Power Relations

\section{AN EXAMPLE - ACTIVE COOLING OF BPX-AT}

As an example, we consider the previously proposed BPXAT design for a DT experiment, whose plasma parameters appear in Table $2 .{ }^{12}$ It turns out that it is even possible to modify the BPX-AT design to provide for arbitrarily long pulse operation, but perhaps with some increase in stress.

The BPX-AT TF coil design (see Figure 10) relied on inner leg half-turns of strong $\mathrm{BeCu}$ conductor material, wedged in the "nose" region in order to be self-supportin for radial loads and thus not require significant additional support structure. OFHC copper conductor was planned for their lower stress outer leg half-turns. The two conductor materials were to be welded together at top and bottom to form each TF coil conductor turn. The TF coils were planned to operate without active cooling, adiabatically heating up during each pulse from liquid nitrogen temperature to near room temperature. At BPX-AT's full 10 Tesla design field, the expected flattop time duration available was limited to 10 seconds.

Table 2: BPX-AT Parameters

\begin{tabular}{|l|l|}
\hline Parameter & Value \\
\hline Plasma Major Radius R & 2.0 meters \\
\hline Plasma Minor Radius a & 0.5 meters \\
\hline Aspect Ratio & 4 \\
\hline Elongation $\kappa_{95}$ & 2 \\
\hline Triangularity $\delta_{95}$ & $0.2-0.3$ \\
\hline Toroidal Field $\mathrm{B}_{\mathrm{T}}$ & $10 \mathrm{Ts}$ \\
\hline Plasma Current $\mathrm{I}_{\mathrm{P}}$ & $6.25 \mathrm{MA}$ \\
\hline Fusion Multiplier Q & 5 \\
\hline
\end{tabular}

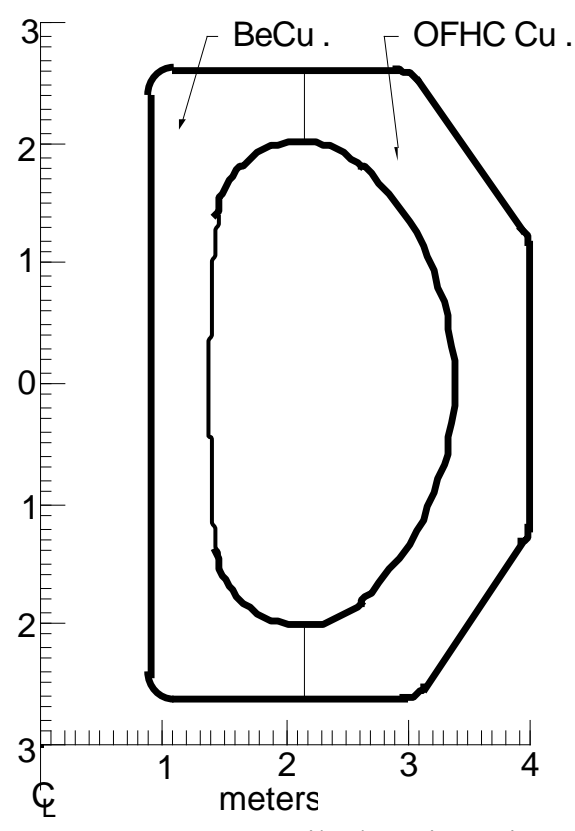

Figure 10: BPX-AT TF Coil Elevation View

The designed maximum TF current density ranges from 18.0 MA $/ \mathrm{m}^{2}$ in the OFHC copper outer legs to 30.72 $\mathrm{MA} / \mathrm{m}^{2}$ the $\mathrm{BeCu}$ "nose region. Assuming active cooling effectiveness in maintaining average conductor temperature at $77^{\circ} \mathrm{K}$, Figure 1 predicts average resistivities of $2 \mathrm{n} \Omega-\mathrm{m}$ and 
$10 \mathrm{n} \Omega-\mathrm{m}$, respectively. Heat dissipation without removing any conductor for cooling channels is then $\mathrm{P}^{\prime}=0.65 \mathrm{MW} / \mathrm{m}^{3}$ in the OFHC copper outer legs, but $\mathrm{P}^{\prime}=9.44 \mathrm{MW} / \mathrm{m}^{3}$ in the $\mathrm{BeCu}$ inner leg nose region.

Half-turn cooling with flow path lengths near $\mathrm{L}=5$ meters could be used for the OFHC copper outer legs. For $\mathrm{P}^{\prime}=0.65 \mathrm{MW} / \mathrm{m}^{3}$, Figures 6 - 9 optimally recommend removing 4 percent of the conductor volume to form $\mathrm{D}=1$ centimeter hydraulic diameter coolant channels through which subcooled liquid nitrogen flows at $10 \mathrm{~m} / \mathrm{s}$ coolant velocity. Total steady power for electrical dissipation plus pumping increases only about $4 \%$ above the power initially required at the start of a pulse without active cooling.

On the other hand, $\mathrm{L}=5$ meter half-turn cooling of the $\mathrm{BeCu}$ inner legs does not appear attractive. With $\mathrm{P}^{\prime}=9.44 \mathrm{MW} / \mathrm{m}^{3}$, Figures 6 through 9 optimally recommend removing 17 percent of the conductor to make room for coolant channels through which liquid nitrogen flows at $24 \mathrm{~m} / \mathrm{s}$, or removing 28 percent of the conductor material for liquid nitrogen flow constrained to $12 \mathrm{~m} / \mathrm{s}$. Either way, stresses would rise substantially.

But there is another flow path geometry possible for the BPX-AT TF coil. Liquid nitrogen flow can be radial, from the TF coil's "inside" which faces the plasma to its "outside".Because the BPX-AT uses a wedged design, it is structurally possible to provide coolant supply and return manifolds on both "inside" and "outside" of the coil turns. With this geometry the coolant channel length in the "nose" region is about $\mathrm{L}=0.5$ meter. For $\mathrm{P}$ ' $=9.44 \mathrm{MW} / \mathrm{m}^{3}$, Figures 6-9 then optimally recommend removing $3.4 \%$ of the $\mathrm{BeCu}$ conductor to construct flow passages with hydraulic diameter $\mathrm{D}=1.5$ millimeters and through which liquid nitrogen flows at $9.6 \mathrm{~m} / \mathrm{s}$. The total steady power for $\mathrm{BeCu}$ dissipation and cooling is then about 5 percent higher than the initial dissipation for the adiabatic design.

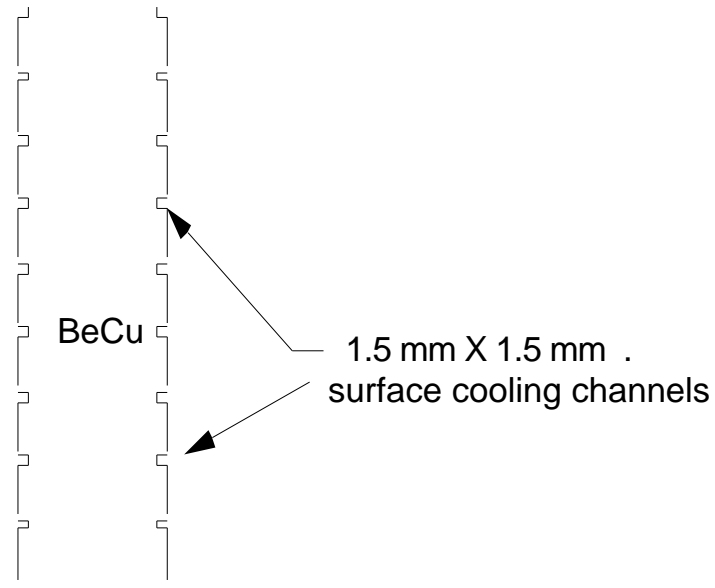

Figure 11: Cooling ChannelsView From Plasma

Figure 11 depicts surface locations on one TF turn for these radial flow channels. Although this channel placement is simple and removes only 3.4 percent of the conductor volume, it eliminates $23 \%$ of the area effective for wedging support of radial loads. This reduction in wedging area will directly increase the peak conductor stresses. On the other hand, active cooling reduces stresses caused by thermal gradients; in particular the significant thermal stress which develops in the adiabatic design at the junction between $\mathrm{BeCu}$ and OFHC copper conductors is almost completely eliminated in the actively cooled design.

\section{CONCLUSION}

Intermittent, low duty cycle, long pulse fusion experiments with self-heated DT plasmas can be implemented using cheap, robust, conventional, high magnetic field copper electromagnets designed for thermally steady active cooling with subcooled liquid nitrogen. Such magnet designs avoid many of the problems associated with delicate and costly superconductors, and could permit substantially lower costs and shorter times for magnet technology development, for device construction, and for operations overhead.

With today's tight fusion budget pressures and receding fusion development schedules, the author believes it prudent to adopt actively cooled copper magnet technology instead of superconductors for fusion's major next step experiments.

\section{REFERENCES}

1. L.Bromberg, et al, "A Long-Pulse Ignited Test Experiment- (LITE)”, Nuclear Technology/Fusion V4; 9 (1983)

2. A. TANGA et al, "A High Performance and Long Pulse Tokamak", EURATOM-ENEA, CentroRicercheEnergia, CP6500044 Frascati, Rome, Italy (1991)

3. E.A.Chaniotakis, et al, "Possibilities for Long Pulse Ignited Tokamak Experiments using Resistive Magnets", M.I.T.PlasmaFusionCenter, Cambridge,MA02139, (1991)

4. R.Woolley, "Design Study of Copper Toroidal Field Coils with Bow Shaping, Demountable Sliding Joints, and Active Liquid-Nitrogen Cooling", Proc. ANS Annual Meeting, June1996 (Reno)

5. T.Adair et al, "High Field Solenoid Magnet with Liquid Nitrogen Cooling", Rev.Sci.Instr. 31 No.4 (1960),p416-418

6. J.Gerhold, "Dielectric breakdown of cryogenic gases and liquids", CRYOGENICS, October 1979, p571-584

7. R.E. Kronauer, "Optimal Design Of Fluid-Cooled Electromagnets", High Magnetic Fields, Proc.Intl.Conf.on High Magnetic Fields Nov.1961, ed.H.Kolm,p116-138,MITPress/JWiley\&SonsInc, 1962

8. R. Fox, Introduction to Fluid Mechanics, Ch8, John Wiley \& Sons Inc, New York, 1985

9. E. Eckert \& R. Drake, "Heat and Mass Transfer", Ch8, McGraw-Hill Book Company, New York, 1959

10. R. Scott, Cryogenic Engineering, p277-283,D.Van Nostrand Company,Inc., Princeton New Jersey, 1959

11. R. Barron, Cryogenic Systems, p474, Oxford University Press, New Yourk, 1985

12. D. Meade, W. Reiersen et al, "BPX-AT Executive Summary", Internal PPPL Report, March 1992 